\title{
A Metáfora na literatura Japonesa: uso de mimese e onomatopéia nos contos de Século XX
}

\section{Metaphor in Japanese literature: use of mimesis and onomatopoeia in 20th century tales}

\author{
DOI: $10.46814 /$ lajdv2n6-003
}

Recebimento dos originais: 01/09/2020

Aceitação para publicação: 30/10/2020

\author{
Tomoko Kimura Gaudioso \\ Doutora em História pela Universidade Federal de Santa Maria \\ Instituição: Universidade Federal do Rio Grande do Sul \\ Endereço: Avenida Bento Gonçalves, 9500, prédio 43221- Bairro Agronomia, Porto Alegre - RS, \\ Brasil \\ E-mail: tomokogaudioso@yahoo.com.br
}

\section{RESUMO}

Ao ler obras literárias japonesas, deparamos com freqüência em metáfora cujo seu uso possui conotação apelativa aos cinco sentidos do corpo. A língua japonesa caracteriza- se pela abundância de metáforas que recorre a sons, imagens e formas e estados das personagens e objetos, os quais podem classificá-los de onomatopéia e mimese. No cotidiano do povo japonês, o seu uso é freqüente na linguagem oral, ocupando o seu lugar como complemento nominal ou advérbio, sintetizando a mensagem de fala, o qual os escritores japoneses de diversas épocas recorrem a esse recurso para escrever suas obras. Alguns escritores como Miyazawa Kenji (1896 - 1933) recorreu ao uso abundante da metáfora, de modo que ao ler a sua obra, necessita "ativar" os cinco sentidos do corpo, ou seja, visão, olfato, tato, gosto e audição, proporcionando a sensação tridimensional do conteúdo do texto ao leitor. Ao estudar literatura japonesa já traduzida para a língua portuguesa, constatamos que as metáforas presentes na língua original simplesmente desaparecem ou são substituídas pela metáfora personificada ou sinestesia. Assim, a fim de compreender os textos que contenham metáforas em língua japonesa, se faz necessário identificar e pesquisar uma nomenclatura lexicológica ou outra expressão adequada em língua portuguesa, assim como outros recursos possíveis a fim de minimizar a omissão ou distorção das traduções de textos originais. O presente trabalho, atualmente em fase de leitura bibliográfica e de coleta de termos metafóricas dos contos e poemas de Miyazawa Kenji , tem como objetivo identificar e agrupar esses elementos miméticos, a fim de criar banco de dados das expressões metafóricas onomatopéicas e miméticas em língua japonesa. Em relação a representação de sons e estado físico-sensorial dos fenômenos da natutreza, tentou-se reproduzi-los utilizando o recurso da aplicação de silabário do alfabeto romano, em estilo Hepburn, de modo que no original, encontram-se escritos em silabário e ideogramas japoneses, alguns dos quais possuem identidade metafórica visual, poderão ser explanados em oportunidades futuras.

Palavras-chave: Miyazawa Kenji, metáforas, autores japoneses modernos, onomatopéia.

\section{ABSTRACT}

Reading Japanese literary work, often face a metaphor whose use has connotations appealing to the five senses. The Japanese language is characterized by an abundance of 
metaphors that uses sounds, images, shapes and states of characters and objects, which can sort them onomatopoeia and mimesis. In the life of Japanese people, their use is frequent in spoken language, taking its place as a nominal complement or adverb, summarizing the message of speech, which the Japanese writers of different ages use this feature to write his works. Some writers such as Miyazawa Kenji (1896 - 1933) resorted to the abundant use of metaphor, so that reading his work, you need to "activate" the five senses, namely sight, smell, touch, taste and hearing, providing three- dimensional feel to the content of the text to the reader. While studying Japanese literature already translated into Portuguese, we find that the metaphors present in the original language simply disappear or are replaced by personified metaphor or synesthesia. Thus, in order to understand the texts that contain metaphors in Japanese language, it is necessary to identify and search for a naming lexicological or other adequate expression in Portuguese as well as other possible resources in order to minimize the omission or misstatement of translations of original texts. This work, currently in reading literature and collecting terms of metaphorical stories and poems by Miyazawa Kenji, aims to identify and group these elements mimetic in order to create a database of metaphorical expressions, onomatopoeia and mimesis in Japanese. In relation to the representation of sounds and the physical-sensory natural phenomena, we tried to description them using the feature of applying primer of the Roman alphabet in Hepburn style, so that in the original, are written in calligraphy and Japanese ideograms, which some have metaphorical visual identity, will be explain in future opportunities.

Keywords: Miyazawa Kenji, metaphor, modern Japanese authors, Japanese modern author, onomatopoeia.

\section{INTRODUÇÃ̃O}

Diferentemente da língua portuguesa que possui léxico mais complexo como verbo para representar sons, vozes e estado da natureza, a língua japonesa é repleta em onomatopéias e mímeses, tanto na linguagem escrita como na oralidade. Estas, apresentados normalmente em sons silábicos curtos e repetidas duas vezes, apela para os cinco sentidos humanos fazendo com que o receptor da mensagem sinta ou perceba a mesma percepção/sensação do autor. Ao depararmos em textos de autor como Miyazawa Kenji, rico em onomatopeias e outros elementos metafóricas, faz- nos reafirmar que há "relação entre sons e sentido" nos "seus diversos níveis e significante" (JACOBSON, 1973).

Embora alguns pesquisadores afirme que "o poeta torna-se um 'lingüista das imagens', testando práticas discursivas, verificando na própria escrita a eficácia comunicativa de diferentes relações sintagmáticas e paradigmáticas (ALVES, 2002:3) , utilizando-se dos jogos de subsistemas linguísticos tais como elemento fonológico, o morfológico, o sintático e o semântico a fim de expressar o grau elevado de significação do estado da sua alma, parece que isso abrange todas as formas de expressão humana, incluindo a prosa e linguagem do cotidiano, especialmente tratando-se da língua japonesa. 
A língua japonesa caracteriza-se pela abundância de metáforas que recorre a sons, imagens e formas e estados das personagens e objetos, os quais podem classificá- los de onomatopéia e mimese. O som e representação fonética do "estado físico" da natureza é abundante nas expressões usados diariamente, as história em quadrinhos estão repletos de sons onomatopeicos complementando a informação dada pela fala das personagens. No cotidiano do povo japonês, o seu uso é freqüente na linguagem oral, ocupando o seu lugar como complemento nominal ou advérbio, sintetizando a mensagem. Esse recurso, a utilização da metáfora para apelar aos cinco sentidos e com isso expressar o signiificado é amplamente utilizado pelos escritores japoneses de diversas épocas.

Alguns escritores como Miyazawa Kenji (1896 - 1933) recorreu ao uso abundante da metáfora, de modo que ao ler a sua obra, necessita "ativar" os cinco sentidos do corpo, ou seja, visão, olfato, tato, gosto e audição, proporcionando a sensação tridimensional do conteúdo do texto ao leitor. Assim, este trabalho mostra as formas pelos quais a metáfora se apresenta nas obras desse autor, tomando-se como base uma obra em prosa e uma poesia, diagnosticando-a conforme suas peculiaridades.

\section{A CONCEPÇÃO DA METÁFORA SEGUNDO LACOFF E AS OBRAS DO KENJI}

Os teóricos clássicos, desde época de Aristóteles, tem referido como metáfora como aquela linguagem utilizada diferentemente em seus sentidos normais diárias. Em teorias clássicas da linguagem, a metáfora era vista como uma questão de linguagem exclusiva do mundo poético, i.e., se afirmava que a linguagem cotidiana não tinha metáfora pois este seria mecanismos linguístico fora do âmbito da linguagem convencional diária.

Segundo Lakoff e Johnson (2002), por seu turno, afirmam que a metáfora não deve ser percebida apenas como uma figura de linguagem que é aplicada somente para enfeitar a poesia. Pelo contrário, eles afirmam que a metáfora exercer forte influência sobre o nosso pensamento, sendo que o seu efeito atinge até sobre o nosso comportamento, chegando a reger as ações do ouvinte e ou leitor de uma linguagem com teor metafórico. Deduz-se, portanto, que as metáforas estão fortemente presentes na vida cotidiana, como ocorre na língua japonesa que, talvez por ter constituição cultural baseada na percepção de fenômenos naturais do que ações humanas, procurou reproduzir foneticamente as percepções sonoras em metáforas, sobremaneira ao onomatopeia, mimese e simile, além dos denominados $j i-y u$, metáfora ideográfica, i.e., uso de determinado ideograma ou parte dele para feitos de alusão quento a seu significado original. 
Conforme Itaya (1999:3), Kenji expressou em suas obras as sensações captadas da natureza e percepção do meio em forma de sketh do seu imaginário ou da sua percepção utilizando metáforas. Essas sensações e percepções são mais descritivos, apelando-se aos cinco sentidos, i.e., sentido visual, olfativo, auditivo, tato e paladar, aguçados que, ao ler suas obras, traz ao leitor a sensação de vivenciar o conteúdo do próprio texto.

Nos contos de Kenji, a presença de metáfora é constante, e de mameira peculiar, visto que esse autor recorre aos conhecimentos de ciência química e física ao descrever as passagens da sua narrativa ou percepção poértica do mundo.

Ooka (1978) diz que:

Pode se afirmar que o lado subjetivo como pensamento, sentimento e sujeito são quase ausentes. A consciência do Kenji tende sempre aos objetos. Parece que ele setá compenetrado em compilar a imagem que seu sentido de visão e audição, capturando-a no papel, no estilo de linguagem oral... (OOKA, 1978)

As obras de Kenji são repletas de metáforas, sobremaneira de giongo, a representação fonética de sons, o que corresponde a onomatopéia e gitaigo, a representação fonética de estado físico ou sensibilidade, o que podermos denominá-lo de mímese. Por outro lado, esse autor utiliza a metáfora de forma abundante nas suas obras, valendo-se de seus conhecimentos acerca de mineralogia, química e da física, de modo que a forma com que seus textos se desenvolve apelando aos cinco sentidos. Em outras palavras, o giongo apela-se a audição, o gitaigo à tato e visão, símile ao olfato e ao gosto.

No Japão, o giongo é usado com grande frequiência nos mangás, i.e., históiria em quadrinhos, para descrever estado e ação das personagens.

Alguns pesquisadores como Takahashi (2007:123-137) prefere manter as onomatopéias presentes no texto do Kenji como pode se perceber no artigo publicado na revista Estudos Japoneses, como na parte do conto que descreve o movimento de fechar e abrir de pálpebras com brilhar nos olhos, o barulho de tosse, bater das palmas, como abaixo transcritos:

Frase 1: "A raposa virou seu corpo e seus olhos cintilaram, pachi, pachi, quando ela apontou com as patas o interior da floresta."

Frase 2: "Limpando a garganta, ehen, ehen, Konzaburo apareceu, saindo do lado da cortina..."

Frase 3: "Todos bateram as palmas alegres, pachi, pachi." 
O uso de onomatopéia da língua japonesa segundo ela, perde seu sentido inicial a ser traduzido para o português, preferindo preservá-la no original. Entretanto, na forma como está traduzida, a sua preservação produz sensação de redundância ao invés de enfatizar o seu significado.

Embora Takahashi afirme que "o recurso de traduzir via não-tradução, para revelar a importância do conceito original", tomando como base o comentário de Seligmann-Silva (2005:185-186), propondo, assim, um glossário de onomatopéia, conforme língua-alvo, poderia mesmo assim, recorrer-se a outro recurso metafórico em conformidade com aspecto lingüístico e cultural da língua que será traduzido.

No caso da língua portuguesa, muitos sons naturais são incorporados à língua em forma de verbos, adjetivos e substantivos, paronomicamente, de modo que o falante e o leitor usamnos sem perceber à primeira vista. No caso da língua japonesa, a fartura da onomatopéia e mímese contrapõe-se à escassez de palavras com funções paronomásticas.

A título de exemplo, essas formas se apresentam comumente em sons que os animais emitem e no caso da língua portuguesa, se apresenta em forma de verbos tais como mugir, cacarejar, miar, piar etc. Por outro lado, na língua japonesa, isto é representado por verbo naku, que significa emitir som, acrescido de onomatopéia correspondente a cada animal, i.e., moo to naku, kokekokko to naku, nyaa nyaa to naku, piyo piyo to naku, etc, respectivamente a vaca, galinha, gato, pinto etc.

Conforme Nakamura (1980:10-11), a metáfora é usado para dois objetivos distintos: a primeira, para esclarecer uma informação que o receptor da mensagem não conheça claramente; outro, para enfatizar uma determinada idéia. O uso de onomatopéia e outras formas de metáforas nas obras literárias, nesse sentido, é usado comumente para enfatizar a mensagem do texto, como ocorre nos textos de Kenji.

Em se tratando de metáforas de modo geral, os onomatopéias e mimeses recebem tratamentos diferenciados dos demais classes por ser abundante e abrangente, tanto em quantidade quanto qualitativamente, visto que apelam para os sentidos táteis, olfativas e visuais de forma direta, mais no sentido cognitivo sensorial do que compreensão lingüísticotextual.

Desta forma, nesta pesquisa pretendeu identificar metáforas presente em suas obras, tanto em prosa como nos poemas para analisar de que forma elas se manifestam. 


\section{METODOLOGIA UTILIZADA}

A metodologia para identificação de metáforas presentes nas obras de prosa e poesia, se consistiu em destacar as descrições metafóricas conforme categorias e classificálas. Como referência, para a prosa, analisou-se inicialmente a obra infantil "Karasu no hokuto hichisei (Ursa Menor dos corvos)", escrito em 21 de dezembro de 1921, onde está presente os elementos identificatórios das metáforas peculiares nas obras do Kenji. Nesta obra, pode se perceber principalmente a personificação, onomatopéia e metáfora propriamente dita. O conto, escrito em língua japonesa, descreve a reação do bando de corvos num entardecer de inverno. Entretanto, ao personificar cada elemento do bando e sua reação diante da chegada da noite e o raiar do luar, cria o efeito ora grotesco ou mesmo cômico ao texto, conduzindo os leitores ao mundo do imaginário fantástico.

O conto foi traduzido na sua íntegra para o português, tentando preservar os elementos metafóricos de melhor forma possível, no entanto, muito se perdeu na transcrição para língua-alvo, principalmente as onomatopéias e mimeses tais como representação fonética do cintilar das neves e o momento do surgimento da lua na noite escura como trinca que aparece numa trinca numa lâmina de aço. Aliás, em se tratando deste autor, o leitor precisa ter conhecimento científico bastante razoável sobre propriedades químicos e físicos de elementos e de objetos, visto que em muitas obras encontra elementos como alusão a característica dos mesmos, de forma científica e consistente, visto que o autor era inclusive cientista e conhecedor de estudos dessa área.

Em relação ao poema, analisou-se o poema “Annelida Tänzerin” (Anelídeo Dançarino), escrito em 20 de maio de 1922, extraído da antologia poética "Haru to Shura" (Primavera e Ashura), por ser uma das primeiras obras poéticas que o próprio Kenji fez questão de ser publicado.

Nestas obras o autor equipara as personagens, objetos e fenômenos físicos da natureza, a sons e característicos físicos de objetos e ambientes, usando principalmente os recursos da onomatopéia, metáfora propriamente dita e efeitos visuais em formas de grafias, tanto de letras clássicas gregas, sistema de silabário japonês, os hiragana e katakana. Embora o texto traduzido não preserve integralmente a metáfora presente no original, percebe sua presença enriquecendo o conto, assim como o poema.

A classificação e aplicação de tais onomatopéias e mimeses não são comuns nas línguas ocidentais, de modo que para identificá-las conceitualmente tais palavras, recorreu-se ao dicionário japonês-inglês de onomatopéia e mimeses japonesas (CHANG, 1990). 


\section{RESULTADOS OBTIDOS}

Em relação a texto em prosa, constatou-se a presença de seguintes elementos que, dada a formatação do texto solicitado em língua ocidental (inglês ou português), ficou restringido a utilizar alfabeto ocidental para representá-las foneticamente.

No Conto "Karasu no Hokutoshichisei" (A constelação da Ursa Maior e os corvos), em forma de prosa, aparecem as metáforas como a seguir, de tal forma que exige do leitor maior conhecimento sobre própria metáfora como pode ser percebido através dos exemplos a seguir.

Exemplos:

- Usui hagane no sora (céu formado por lâmina de aço forjado) = o céu de cor cinza escura é visto como lâmina de aço, sendo que nesse trecho o autor não recorre à expressão gramatical no you que tornaria a palavra hagane um símile.

- Yakareta hagane no sora (céu de aço incandescente) = cor do céu ao entardecer é equiparado ao aço em brasa.

- Atarashiku yakareta hagane no sora (céu de aço torrado recentemente) = aqui também se recorre a similitude, mas igualmente não se pode afirmar definitivamente que é um símile no conceito recorrente do termo pois essa equiparação ocorre a nível de equiparação visual entre o aço incandescente e ocrepúsculo.

- Chiisana hoshi ga ikutsuka gappei shite bakuhatsu wo yari...(algumas estrelinhas se juntaram e explodiram...) = Brilho das estrelas; neste trecho da obra, o brilho das estrelas é substituído pela imagem da explosão de umabomba.

- Karasu no giyuu kantai (a frota de corvos)

"Todos colocaram ciroulas negras apressadamente...Finalmente,surgiu trinca no céu formado pela lâminande açoddependuraram- se vários braços longos e sinistros tentando pegar os corvos e puxá-los para outrolado do teto do céu... Não, não é isso. Surgiu a lua.” (MIYAZAWA, 1922)

Neste trecho, o autor acaba explicando a metáfora que usou no parágrafo anterior, de forma concreta, informando o leitor que toda descrição do parágrafo anterior referia-se ao fenômeno do surgimento da lua, equiparando-o a rachadura que se forma na superfície do aço fino.Os raios da lua são descritos em forma de braços compridos que pendem da rachadura, tentando alcançar os corvos. (A constelação de Ursa Maior e os corvos)

Nesta mesma metáfora, está inserida ainda, a onomatopéia para descrver o movimento pelo qual essa rachadura é formada, "pichiri", o que corresponde ao som "craque", em português. Utilização do recurso da enfatização do significado através do acréscimo do 
ideograma representando $k i=$ esgarçar, romper e retsu $=$ rachadura. $\mathrm{O}$ autor acrescenta o ideograma esgaçar na palavra rachadura e força o sentido, mantendo- se a leitura desejada (hibi), de modo que a junção de ideogramas passa a ter efeito de $j i$ - $y u$, já mencionado anteriormente, uma espécie de jogo de imagens que o ideograma permite realizar. Por outro lado, não há utilização da expressão gramatical "no youna (que e se assemelha a, como)", i.e. , o autor não formula a frase "céu como aço", utilizando o recurso de similitude.

Do mesmo modo, utiliza-se igualmente, a partícula "to" (de forma tal, deste modo...) ao descrever formação da rachadura, representando um fenômeno natural por si só em vez da partícula ni (também significando de forma tal..., deste modo...) que, na sua utilização, passa-se a perceber que o fenômeno natural ocorrido é efeito ou resultado de alguma ação ou movimento externo. Essa diferença é sobremaneira observada por Tanaka(1990:195-196) que, ao se referir a utilização dessas partículas nas onomatopéias de forma aglutinada, distingue-se abstratamente se houve interferência externa à ocorrência de um determinado fenômeno. Assim,

A língua japonesa foi expressando a sensação percebida da natureza em forma de palavras e não foi apropriando objetos e coisas de forma abstrata. Assim, na língua japonesa, desenvolveu-se onomatopéia e mímese, formado por sons próximos ao fenômenos naturais. (TANAKA, 1990:194)

Essa equiparação do estado do objeto ou fenômeno físico à realidade é posteriormente explicada pelo próprio autor nos parágrafos posteriores, como nos trechos a seguir:

Finalmente, no céu levemente metálico, abriu-se uma justa fenda, dividindo o céu em dois, e dessa rachadura desceram muitos braços, longos e perversos, que tentaram agarrar os corvos e levá-los em direção ao ápice dofirmamento. (MIYAZAWA, 1922)

Mais adiante, o texto esclarece o verdadeiro acontecimento, o fenômeno natural compreensível a qualquer leitor, através do seguinte trecho, como se desculpasse da expressão anterior, escrito como um monólogo que é compreensível apenas ao próprio escritor.

Não, não foi isso que aconteceu. Não foi bem assim.

Surgiu a lua. Uma lua achatada e azulada em seu vigésimo dia, que das montanhas ao leste chorava e subia ao firmamento. (MIYAZAWA, 1922)

Passamos agora a analisar um dos poemas publicado na fase inicial do autor. No poema Aneridae danzerin (anelídeo dançarino) foram identificadas seguintes usos de metáforas. Em primeiro lugar, ao escrever seu título, o autor escreve-o em ideograma, 
coloca leitura fonética em caractere fonético japonês representando a língua alemã, sendo que na época ele estudava esperanto. Ao representar os vermes na água se remexendo, equipara-os com letras gregas clássicas. $\mathrm{O}$ que o leitor percebe ao avistar a impressão, são vários riscos e linhas contorcidos e, num segundo momento, percebe-se que se trata de letras ou algum símbolo qualquer. $\mathrm{Na}$ verdade, Kenji insere em sua poema várias letras gregas que, estando escritas em minúsculo, parece reproduzirem a imagem de vermes se contorcendo.

Como se não bastasse, ainda recorre a outro recurso visual, utilizando-se de ideogramas que significa anelídeo dançarino, anexa as letras fonéticas em japonês reproduzindo os sons em alemão. Ou seja, o próprio título é escrito em três níveis diferentes da língua: o primeiro em ideograma kanji, possibilitando à compreensão a nível cognitivo, o segundo, em katakana, i.e., em caractere de representação fonética e, terceiro nível, em língua alemã, visto que a representação fonética não é a da palavra em japonês mas alemã. Analogicamente, a grosso modo, poderia-se afirmar que o ideograma kanji corresponderia a langue e o katakana a parole já que apesar de ser representado por símbolos fonéticos em japonês, a pronuncia ali reproduzida é palavra alemã.

$\mathrm{O}$ autor desde início faz um brainstorming na mente do leitor, sem que alguém percebesse desses detalhes, já que esse tipo de estruturação da escrita em língua japonesa é muito recorrente.

Outra característica das obras de Kenji é uso abundante de características físicas ou químicas num conceito mais científico que popular de modo que ao ler suas obras requer do leitor certo conhecimento científico.

Eis algumas metáforas que aparecem no poema:

- mizu zoru = estado sol da água, contrapondo-se ao estado gel, i.e., líquido sem viscosidade;

- kanten no eki (solução de agar-agar) = ambiente opaco e esbranquiçado, em estado geleificado (estado gel);

- kin no bara (rosa de ouro, não se refere a cor "dourada") e sim o elemento químico $A u$ ao equiparar o sol como rosa de ouro.

- arabesuku no kazari moji (letras arabescas) = representações de anelídeos se movendo na água;

- shinjyu (pérolas) = kuuki no awa (bolhas de ar) 
- Anelídeos se contorcendo é representado por letras minúsculas gregas $8, \gamma$, e , 6 e $\alpha$.

- mizuzoko no kuroi mokuhen (pedaço de madeira escura no fundo d'água)=kemushi ka nameko no you $)=$ parece ser bicho cabeludo ou pepinod'água) - neste trecho, a descrição do objeto "madeira" é feita de forma indireta com utilização da partícula no you que utilizase para descrição de similitude dos objetos, estados e ações.

\section{CONCLUSÃO}

As duas obras de Miyazawa Kenji aqui apresentadas mostram diversos aspectos da metáfora presentes na língua japonesa. O primeiro aspecto é a personificação das personagens, o que se pode observar em karasu to Hokuto Shichisei, em que os corvos são representados por frota de canhoneiros e encouraçados, cada qual assumindo os postos militares como se seres humanos fossem.

Por outro lado, as expressões gramaticais utilizados para metáforas no you na (aquilo que se parece com) e $\sim$ no you ni (agir como se fosse) estão presentes em apenas dois momentos do texto, de modo que percebe-se a intenção do autor em evitar uma equiparação de uma coisa ou situação à outra, no mesmo plano de leitura ou frase. Quando há necessidade de acrescentar informações, esse o faz com acréscimo de textos explicativos como ocorre na parte da narrativa em que a lua surge na escuridão da noite, lançando sobre os corvos o luar, deixando-os apreensivos.

Outro aspecto é a presença abundante de onomatopéias e mimeses nos textos, como ocorre na obra analisada, com presença sobremaneira de mimeses que conta mais de quatorze palavras, alguns delas repetidamente usadas. Em se tratando do poema, além da metáfora comumente presente nos textos ocidentais, a utilização de recursos visuais e gráficos enriquece o seu conteúdo, pela incitação da inteligência cognitiva daqueles que a lêem.

De modo geral, essas metáforas são presentes em obras de outros escritores modernas e contemporâneos japoneses, em maior ou menor grau, muitos inexistentes na língua portuguesa, de modo que para sua compreensão pretende-se elaborar no futuro, o levantamento e tradução das onomatopéias e mimeses japonesas. 


\section{REFERÊNCIAS}

ALVES, Ida Ferreira. A linguagem da poesia: Metáfora e conhecimento. In: Tterra roxa e outras terras - revista de estudos literários v. 2. Rio de Janeiro: Universidade Federal Fluminense, 2002.

ITAYA,Eiki. Miyazawa Kenji no, tanka no youna. Toquio: Nippon Housou Shuppan Kyoukai. 1999.

LAKOFF, George. Metáforas da vida cotidiana/ George Lakoff, Mark Johnson[coordenação da tradução Mara Sophia Zanotto] - Campinas, SP: Mercado deLetras; São Paulo: Educ, 2002.

KENJI, Miyazawa. Aneridae danzerin. In: Primavera e Ashra. Obras completas de Miyazawa Kenji, v. 1.. Toquio: Chikuma Bunko, 1988.

NAKAMURA, Akira. Hiyu hyougen jiten.Toquio: Kadokawa Shoten, 1980.

OOKA, Shohei. Sobre tanka dos poetas. In: A força das palavras. v.3. Toquio: Hanajinjya, 1978.

SELIGMANN-SILVA, Márcio. O local da diferença-ensaios sobre memória, arte, literatura e tradução. São Paulo: Editora 34, 2005.

TAKAHASHI, Márcia Hitomi. Tradução do conto Atravessando a neve, de Miyazawa Kenj: alguns aspectos. Estudos Japoneses, n. 27, 2007.

TANAKA, Toshiko. Guidance on japanese grammar. Toquio: Kindaibungei-sha, 1990. Aozora bunko http://www.aozora.gr.jp/ 